\title{
Study of Effective Cultural, Social Economical Factors on Making Work Stress among Workers in Mobarakeh Steel Complex
}

\author{
Mohammad Reza Iravani \\ Assistant Professor, Department of Social Work, Islamic Azad \\ University Khomeinishahr Branch, Daneshjou Blvd, Iran. \\ E-mail: iravani@iaukhsh.ac.ir
}

Received: January 4, $2011 \quad$ Accepted: March 28, 2011 doi:10.5430/ijba.v2n2p87

\begin{abstract}
The aim of the study is to analysis of effective cultural, social economical factors on making work stress among workers in Mobarakeh Steel Complex. The present research method is measurement base with survey of questionnaire that is placed on descriptive research, according to research's results it can be considered as practical one. Studied statistical society is all workers of Mobarakeh Steel Complex who are working in different level of work and vacation. They have been distributed by kurgan formula; number of 100 persons is randomly selected. In this study questionnaire is used for gathering information 7 containing of 20 questions relating to 5 assumptions that its purpose is measurement of workers' view about causes of work stress. Findings show that level of income, religious opinions, stress base, education level and training while working most important effective factors on stress of working people in Mobarakeh Steel Complex.
\end{abstract}

Keywords: Work stress, Stress base, Religious opinions

\section{Introduction}

Today stress is one of life problems that is considered by industrial societies and construction and total changes of societies from traditional to industrial life. Recent modern society makes stresses that may not been observed in the past and is predominant now. Employment is essential case for continuing human life, so it brings stresses that timely recognition and interference of these stresses can prohibit negative effects. Stress is as one power and pressure. If these pressures and forces are excess of defined limits, they will cause disturb present position and make stress. Therefore, recognition possible ways for interfering and before that recognition the word of stress is very important to decrease stress and we can productive ways with detailed study and interfere timely to prevent or decrease skills of challenge with stress have spread concepts and behavioral and cognitive components. In general, challenging is defined as attempts for increasing compromising with environment or attempt to prevent occurring negative consequences un stressful situation (Lazarus and Foul Colman, 1984)

Researchers consider two important ways of challenging stress including methods of problem based compatibility that have direct activities for changing or correct conditions that are minatory and also methods of trill based compatibility that contain activities or thoughts for controlling undesirable feelings which are resulting from stressful conditions. Process of neutralizing stress is pointed out by deleterious effects of internal and external stressful factor (Samsun, Piers, 1990)

Studies show that people who have low interpersonal conflicts and high social support are resistant against encountering stressful event in the life and repel effectively and show low signs of depression or mental disorders.( Monomer, Bramante, Kennel, Eshtain1986)

Among methods of compatibility with stress, method of religious compatibility has more important role in mental and physical compatibility. Regarding to clinical experts' ideas, religious factors have social, cultural mental, physical and family effects in individual life. (Loin and Wanderpool, 1992)

\subsection{Mental tension}

It is active situation that a person encounters with one opportunity limitation or need 7 is relating to something he tends to do and obtained results are vague and insecure for him and yet important.( Gharib abbas1992) 


\subsubsection{Work stress}

It is interaction between work conditions and an individual characteristic that needs of workplace is more than individual ability. (Hagh Shenas, Ali Mohammad, 1996)

Stress theories: stress perhaps is most common problem of life (Abzari Mahdi, Sarayedaran, Hamid, 1997)

The form of stress is prevalent among people and has different meanings and applys in various grammar forms of work. Work is activity or thought for producing things as economical activity to prepare family (Abzari Mahdi, Sarayedaran, Hamid, 1997)

For example as one noun in the sentence "he suffers stress", as an objective in sentence " today life is stressful and sometimes as verb. In fact, stress is specific side of today life (Khajeh poor, Gholam Reza,1998)

Three patterns of stress that extend in generalized way consider stress as response a person shows against conditions and events. Second group consider it a complex of problem the people encounter it in the environment. In third group it is as interaction between individual characteristics and environmental factors. Although the concept of stress is important for psychologists so many years, first person does stress discussion in the field of medical sciences is Hans Celle in the earlier present century. Physicians conveyed the discussion of relation between specific patterns of many personalities of having certain diseases. However, even in the past work of Cloud Bernard showed that nevertheless changes accrued in the external environment of human, internal system of body should certainly be stable in proper situation. Then Walter Canon in the year 1935, completed his theory 7 presented it in the form of Hemoextacy (Zandi Poor, Tayebeh, 1984)

About correlation between external factor and internal responses of the body, other studies had been done by Wolf and Wolf show that different patients suffer changes in the stomach activity, for example in some patients, changes in excitement situation is accompanying with change in scientific study about blood circulation and stomach discharges. Next years, main point of this of the study was developed and the field of scientific study in medical researches was provided and leaded to the subject psyche, body disorders like ulcer and asthma. All of us experienced such relation among external factors and internal responses like when we concerned or when we are anxiety we fell muddle.

\subsubsection{Introducing point view about stress}

\section{Stress as an internal response}

Hams Celle was one of researchers who describes stress as new phenomenon in the year 1956, Celle paid attention to body responses against requests that it deals with. He believed that this response is one of non special responses and his intent war requests of everybody who is encountering stress. Follow common and similar pattern and this certain pattern called general compatibility. This process has three stages: first stage is syndrome of general response against stressful factors. This distance takes short time to show first resistant response of body following them longer resistant would be achieved. In this stage, changes in the body to make it ready to response immediately heartbeat makes it faster and hypertension are high. Sugar of blood releases to provide due energy for working for example when you pass away the streets and suddenly we find a car quickly comes to you and you move faster or you start to run to save yourself form accident . It is sample response to stress in the warning stage. If stressful factor remains second stage or resistance reaches, in this stage first response that appears in warning stage replaces with response to make longer compatibility (Khajeh Poor, Gholam Reza, 1990)

The concept of Hemoextacy mentioned before plays its role in the play stage; it means that return to equal mood is necessary factor in the body. So necessity of this stage continues attempts of human to make compatibility with stressful factors or habits to it. For example, you consider a worker who works in the factory. After some months he remains such environment, he isn't upset due to noise but we see he suffers headache and he robs his teeth together in asleep. After times he spasms of cervical muscles due to stress of noise such workers learnt to bear work stress due to sever noise of environment but they show physical defects that are felt by stressful noise.

Third stage: In Celle 'view knockout means the body can not eliminate conflict with stressful factor and due energy for continuing compatibility became low and person disables. Then specific side in the third stage is to direct resistance against stress, depression or even death like soldier who knockout because wounds and pressure, hunger, thirst, and anxiety. Celle believed that there is positive s means stress can be as a motive to grow and effective factors for changing, sometimes it is called good stress.

\section{Environmental factors of stress}

Engineers consider stress as product of summing forces that apply on device and set can break it. In year 1930 for first time Adolf Meir generalized this concept and said: physicians enter medical information into tables like past disease 
history, changing job and so on and make tables that may be a plot for after disease. After that Holms and Rae in 1967 generalized this concept, both of them purposed stressful events of life are predominant and human encounter them and they result important changes in the life. Some of these events are obviously stressful like divorce and so on. All events have positive side like permission, gratuity and so no. For this reason, potential negative effects are considered from early human life stress as interaction. Third pattern that Richard Lazarus said is more considerable and called interactive pattern. He believed that when stress occurs that balance between request and references disturb and this balance and imbalance have progressive entity. In addition to it, the pattern is exterminator of influencing environment on individual and vise versa. In this pattern first stage for forming process of stress and conflict is evaluated individual event or specific situation. This evaluation called first evaluation .In these uncomfortable consequences of evaluation damage done, damage occurs while evaluating threat or danger means that it is possible to bear future damage. Lazarus had other evaluation called challenge and when it is succeeded that instead of keeping yourself against consequences you can conflict to reach positive consequences. But second evaluation is including person with possibility of selection tries to determine and select possible ways for facing problems. Interactive pattern is knowledge to subject for conflicting with problems of equipments and references in evaluating future against to event stressful situations is effective. for example a person who loss his work and knows that have relatives give him another place or borrow money, so this chance causes not to see his situation as serious threat. But vice versa, another one sees himself within serious threat may know if he changes his job or he loses his job it is possible to lose his job work can be a motive. Flexibility of this pattern shows both weakness and strength. Based on this pattern, we can consider stress as a combination of noteworthy problems and individual interests that change during the time. On the other hand, references and remedial answers should be applied in stress; on the other hand, they change by passing time.

\subsection{Work stress}

The definition of Work stress is interaction between work conditions and individual characteristics of worker that environmental workplace's request and as a result relating pressures are in the way one can undertake. This definition points out context of relation with environment. Signs of Work stress are including signs.

Mental signs:They re set of emotional and cognitive problems that introduce via inconvenience due to Work stress. Dissatisfaction of job is most prevalent consequences of Work stress. A person who unsatisfied does late to work and is depressive and feel anxiety and unhappiness and his health is endangered and is insular and tired. These cases show mental signs are relating to problems and may cause worse Work stress.

Physical signs:These signs can be recognized more difficult, because while certain work conditions are accompanying with decrease and physical defects, but it is difficult to see these diseases are only effect of work and how many are other result of life fields. Most common signs of physical, viscordial disease are stomach inconvenience, digestive and cetaceous problems, headache.

Behavioral signs:They are two sets: first set is signs refereed directly to working person like increasing consumption of liquors, avidity and jade. Second set referred to behavior that its consequence is organization or machineries. Like absence of work releasing work, what is releasing to inability (exhaustion) we can observe in a person who is unable to do any thing and tired frequently.

Inability regarding to researchers of Piers and Aronson in year 1981is one of main inevitable of Work stress, while this stress remains, they can continue. Inability has three sides: first side is physical exhaustion. Celle in this pattern shows that when stress occurs, stocks of energy of individual finish. By continuing this phenomenon, exhaustion appears one forming component of inability. He complain this sever exhaustion with invasion. Two sides of inability are emotional. When physical stocks decrease because of continuing stressful work condition, it is possible resources of emotional force decreases like prostration and disappointment and satisfactory decreases. Third side is mental exhaustion. In this case, workers behave unexpectedly and review work of stockholder, colleagues or clients. This subject that unable worker cannot observe feelings and requests of there and this theory can be drawn to home while Penis and Aaron point out workers who suffer this problem none only release their work but also release their profession and skill.

In the part of human services negative effects are obvious and deleterious another group of workers who suffer inability remain in the workplace and eventually release their interest to personal and professional development. These persons don't want to accept other suggestion of works that is useful for themselves as if interfere is performed by others. They are workers who wait to retire and exit organization from useless human force.

\subsection{Costs of work stress}

If we look stress as reactive side that every one shows against problems. We collect information Statistics show affected of current behavioral and emotional reactions with number and digit and costs of Work stress is very high and 
determining precise level is difficult. One mental ill patient like depression may cause Work stress. In fact, one of other costs of Work stress show effects of working performance in workplace. For example absence of work is expensive. Great expenses are relating to loss which results in failure of workers who employ sensitive works. (Employees of watchtower of airport)

Another invisible and irreparable damage is family center. Reflection of stress indentifying interpersonal relations particularly spouses, parent, children and damage based on quality life.

\section{Methodology}

\subsection{Importance of research}

Stress perhaps is most common and necessary unavoidable problem of today life and employment for continuing life and society's survival.

Life of everybody is prepared by working and independent of every country is dependent to level and performance of workers. Proper employment and lack of stress and mental pressure of job result in happiness and joyance. Gob affects on all fields of life. It has important role in selecting proper friend, growing children, values social situation, emotional health, family relations, summary of criteria and life dimensions. So attending to cases above, having proper job and lack of work stress and mental pressure has effective significance.

Because of lack of proper job and stress resulting from those all aspects suffer defect and even society go to the naught. So we should know all stages of making stress and also recognizing protective ways and training necessary material and raising individual perception against this subject, they should introduce them to this situation and whatever we can decrease stress resulting from job and mental pressure to give people better life and health and happiness.

\subsection{Purpose of research}

Studying effective cultural, social economical factors on making work stress among workers in Mobarakeh Steel Complex.

\subsection{Research methods}

It is one of measuring one with surveying questionnaire of gathering information. For confirming predicted information of all sample people, Also research descriptive survey is done by discovering present truth with what is present. On the other hand, this research method is done by describing researching and certain event. For this reason, researcher doesn't discuss about cause and effect, of course just how living in the society. This measuring research points out to workers' point views by questionnaire.

Statistical society and samples studied in this study is workers of in Mobarakeh Steel Complex who are working in different surfaces of work and experiences has based on Kurgan formula, number 100 persons are selected accidently and questionnaire are distributed. Device and techniques of gathering information: in this study we use device of questionnaire for gathering information. Those are including 20 questions relating to assumption and ask aim of measuring workers' view about causes of stress work

\subsection{Research assumptions}

It seems that there is a meaningful relation between income of workers and level of stress.

There is a meaningful relation between religious beliefs of people and level of stress.

There is a meaningful relation between social base of worker and level of stress.

There is a meaningful relation between education and level of stress.

There is a meaningful relation between training while working and level of stress.

\subsection{Statistical method}

In this study for confirming assumption or defining it by using average numbers relating to each item of questions about one assumption applied table $\mathrm{x} 2$ ( chi duo)

Research limitation: this study has been done in the condition that workers were stop in the production lines, so one of problems and limitations of research is giving question to people and also lack of enough time for answering to question is another limitation and moreover, lack of proper space different parts. Another limitation of research is contribution among supervisors of unit to deliver question. Therefore, by continuous discussion to make proper field different shift and it takes more time to do. 


\subsection{Test of assumptions}

Based on Chi duo $\times 2$ obtained in the table of Assumption 1 that is equal to 200.023and Chi Dou obtained from guidance table that is equal 9.49 and whereas Chi duo obtained from table is higher than 2 guidance tables, so assumption 1 is confirmed.

\section{Discussion and Conclusion}

By studying and analyzing tables 7 statistics obtained according to research subject studying effective cultural, social economical factors on making work stress among workers in Mobarakeh Steel Complex of Isfahan.

According to Chi Duo calculated in assumption1 is higher than in guidance table so Assumption1 that whatever level of income increases, level of stress increases is confirmed. Therefore, there is a meaningful relation between decreasing income of workers and increasing stress

According to table2 Chi Duo calculated in assumption2 is higher than in guidance table so Assumption1 that whatever people are more stable in religious beliefs, level of stress decreases is confirmed. Therefore, there is a meaningful relation between having higher religious opinions and decreasing stress.

According to table3 Chi Duo calculated in assumption3 is higher than in guidance table so Assumption1 that whatever workers are belonging to higher social base, level of stress decreases is confirmed. Therefore, there is a meaningful relation between having higher social base and decreasing stress.

According to table4 Chi Duo calculated in assumption4 is higher than in guidance table so Assumption4 whatever level of workers' education is higher, level of stress decreases is confirmed. Therefore, there is a meaningful relation between having higher education and decreasing stress.

According to table5 Chi Duo calculated in assumption5 is higher than in guidance table so Assumption5 whatever training while workings is lower, level of stress increases is confirmed. Therefore it causes to decrease creativity and innovation, so stress increases in work place. Then there is a meaningful relation between lack of training while working for workers that decrease innovation of person during working and introducing innovation and increment of stress. So we can say if there is no training while working, repeating work became wastage and organization won't face with proper mobility. According $t$ assumptions and analysis above we concluded following factors have significant role in forming work stress in the workplace:

- Lack of enough information About job, manner of doing it

- Incompatibility wonk with individual characteristics and personality

- Lack of training and enough opportunity for making creativity and innovation

- Lack of base and visual and social support of working people

- Lack of work securing in the future for continuing work

- Lack of proper income for making proper bed for growing and exactly human whether mentally or intellectually

- Lack of different training on work and manner of doing it

- Not observing safety protective principles for worker and occurring financial physical and accidents and correcting family problem and also colleague and organization

Suggestion:

- Studying strategies for increasing incomes and wages and giving proper gratuity for doing better work

- Publish advertising and proper books about causes and motivations of work stress and situation of interfering to prevent them among workers and increasing knowledge of workers about these problems

- Training to raise work yield presenting professional and non professional training workers can make group or remedial team among themselves to solve problems more than discussing problems

- The presence of psychologist or social service and consultation. Replacing workers based on specialty and work division regarding to individual characteristics

- Making proper space for representing suitable solutions for problems in work place, asking workers opinions about making active atmosphere to continue work at certain place

- Motivation to continue work after coming back of reaction or travel. Making proper atmosphere and eliminating amazement about work and assuring work security to work better 


\section{References}

Abzari, Mehdi \& Saraydarian, Hamid, (1997). Management organization and mental pressure, Organ prose of Isfahan.

Bros lee, Schertz, (1987). Surveying and planning educational and professional life, translated by zandi Pooor, Tayebeh, Ferdosi Press

Haghshenas, Ali Moohanmad, (1996). Persian language from tradition to modernization, Magazine of healthy society, $5^{\text {th }}$ year, No.26

Lazarus, R, S \& Folk man, S, (1984). Stress, appraisal and coping.New York: Springer.

Levin, J.S \& Vander pool, H, (1992). Religious factor in physical health and the prevention of illness. New York: Haworth Press.

Monroe, S, M \& Steiner, S, (1986). Social support, life events, and depressive symptoms. Journal of Consulting and Clinical Psychology.

Pier Henry, Lou, (1991). Permanent stress, translated by Abbas Gharib, Derakhshesh press, $1^{\text {st }}$ publish, Mashhad

Randle Ras, M \& Eltimar, Elizabeth, (1998). Translate by Khajeh Poor, Mohammad, press of industrial management organization, $1^{\text {st }}$ publish

Rasel, Michel, (1990). Depression, translated by Khajeh Poor, Gholam Reza, Mina press, Tehran

Sara son, I, G., Pierce, G R, (1990). Social support and interactional processes a triadic hypothesis. Journal of Social and Personal Relationships.

Table 1. Whatever level of income increases, level of stress increases

\begin{tabular}{|c|c|c|c|c|}
\hline Assumption1 & Low & Moderate & High & Total \\
\hline Low & 0 & 0 & 73 & 73 \\
\hline Moderate & 0 & 11.75 & 0 & 11.75 \\
& 1.791 & 1.380 & 8.577 & \\
\hline High & 15.25 & 0 & 0 & 15.25 \\
& 2.235 & 1.791 & 11.132 & \\
\hline Total & 15.25 & 11.75 & 73 & 100 \\
\hline
\end{tabular}

Table 2. Whatever people are more stable in religious beliefs, level of stress decreases.

\begin{tabular}{|c|c|c|c|c|}
\hline Assumption2 & Low & Moderate & High & Total \\
\hline Low & 0 & 0 & 50 & 50 \\
& 13 & 12 & 25 & \\
\hline Moderate & 0 & 24 & 0 & 24 \\
& 6.24 & 5.76 & 12 & \\
\hline High & 0 & 0 & 0 & 26 \\
& 6.76 & 6.24 & 13 & \\
\hline Total & 26 & 24 & 50 & 100 \\
\hline \multicolumn{5}{|r}{}
\end{tabular}

Table 3. Whatever workers are belonging to higher social base, level of stress decreases.

\begin{tabular}{|c|c|c|c|c|}
\hline Assumption3 & Low & Moderate & High & Total \\
\hline High & 80.5 & 0 & 0 & 73 \\
& 64.80 & 10.465 & 5.233 & \\
\hline Moderate & 0 & 13 & 0 & 11.75 \\
& 10.465 & 1.69 & 0.854 & \\
\hline Low & 6.5 & 0 & 0 & 15.25 \\
& 0.423 & 0.845 & 5.233 & \\
\hline Total & 80.5 & 13 & 6.5 & 100 \\
\hline
\end{tabular}


Table 4. Whatever level of workers' education is higher, level of stress decreases.

\begin{tabular}{|c|c|c|c|c|}
\hline Assumption4 & High & Moderate & Low & Total \\
\hline High & 0 & 0 & 84.5 & 73 \\
& 6.76 & 6.34 & 71.40 & \\
\hline Moderate & 0 & 7.5 & 0 & 11.75 \\
& 0.6 & 0.563 & 6.34 & \\
\hline Low & 8 & 0 & 0 & 15.25 \\
& 0.64 & 0.6 & 6.76 & \\
\hline Total & 8 & 7.5 & 84.5 & 100 \\
\hline
\end{tabular}

Table 5. Whatever trading while workings are lower, level of stress increases.

\begin{tabular}{|c|c|c|c|c|}
\hline Assumption4 & Low & Moderate & High & Total \\
\hline Low & 0 & 0 & 20 & 50 \\
& 12.5 & 3.2 & 4 & \\
\hline Moderate & 0 & 17.5 & 0 & 24 \\
& 10.94 & 3.63 & 3.5 & \\
\hline High & 0 & 0 & 0 & 26 \\
& 39.056 & 10.94 & 12.5 & \\
\hline Total & 62.5 & 17.5 & 20 & 100 \\
\hline
\end{tabular}

